\title{
ENTRE TRANSICIÓN POLÍTICA Y NEOLIBERALISMO: EL BARZÓN MEXICANO
}

\author{
Carlos R. Rea Rodríguez*
}

RESUMEN

En el presente trabajo se analiza el estado de la acción colectiva en México en el contexto del agotamiento del modelo nacional-popular y de la instauración salvaje del neoliberalismo. En el texto se pone especial énfasis en el caso del movimiento de deudores nacido a mediados de 1993, conocido como El Barzón. Esta movilización constituye una forma de respuesta organizada de los sectores medios productivos y de servicios del país ante la política de despojo emprendida en su contra por el capital bancario y financiero con el beneplácito del Estado mexicano.

PALABRAS CLAVE: MÉXICO * MOVIMIENTOS SOCIALES $*$ NEOLIBERALISMO $*$ BANCOS $*$ APERTURA ECONÓMICA * CLASE MEDIA URBANA * AGRICULTORES * BARZONISMO * ACCIÓN COLECTIVA

\section{ABSTRACT}

The present work analyzes the state of collective action in Mexico in the context of the exhaustion of the popular-nationalist model and the instalation of unbridled neo-liberalism. It places special emphasis on the case of a debtors movement, known as El Barzón, which began in 1993. This mobilization represents a form of organized response from the mid-level productive and service sectors of the country, in the face of confiscatory policies enacted against them by the banking and finance sectors, with the complicity of the Mexican state.

KEY WORDS: MÉXICO $*$ SOCIAL MOVEMENTS $*$ NEOLIBERALISM $*$ BANKS $*$ ECONOMIC OPENING $*$ URBAN MIDDLE-CLASS $*$ FARMERS $*$ BARZONISM $*$ COLLECTIVE ACTION

\section{INTRODUCCIÓN}

La acción colectiva en México, al igual que en el resto de Latinoamérica, experimenta desde hace algunos años profundas transformaciones. En un contexto histórico marcado por las transiciones político-electorales de orientación democrática y por el predominio del proyecto económico neoliberal en prácticamente todo el Sub-continente, las relaciones entre Estado, sistema político y sociedad, por un lado, y entre Estado y mercado, por otro, se ven cualitativamente 
modificadas. La autonomía creciente entre dichas esferas muestra la tendencial instauración de formas de modernidad en la región bajo el signo de la ambivalencia: por un lado, expresando la consolidación de formas democráticas dentro de la dinámica política (sobre todo en la electoral); por otro, produciendo masas de pobres $y$ de miserables de forma acelerada. Estas mutaciones enfrentan, sin duda, tanto a los actores políticos y sociales, como a quienes pretenden dar cuenta de los mismos, a nuevas condiciones de funcionamiento de la sociedad $y$, por tanto, a considerables retos.

La pretensión general de este trabajo es exponer algunas de las modificaciones fundamentales que la acción social organizada vive recientemente en México, mostrando que este universo de acción está constituido por una pluralidad de segmentos que dan cuenta de la yuxtaposición de procesos de cambio político, económico, social y cultural de naturaleza también diversa. En esta línea de reflexión, presentaré la experiencia de los deudores de la banca en situación de cartera vencida y organizados en una de las movilizaciones sociales más importantes de la última década: el barzonismo ${ }^{1}$.

Como hipótesis general de trabajo sostendré que en México presenciamos la yuxtaposición de procesos con una densidad temporal distinta $y$ con un impacto por consecuencia diferente sobre la dinámica de las estructuras políticas, sociales y culturales de nuestro país. Así tenemos un proceso general y de largo aliento - que no es lineal, aproblemático ni definitivo- de secularización de la vida sociopolítica nacional, consistente, en

Al hablar de barzonismo me refiero a una corriente de movilización social en la que encontramos tres organismos nacionales provenientes de una matriz única: tanto la Alianza Nacional El Barzón, La Unión Nacional de Productores Agropecuarios, Industriales, Comerciantes y Prestadores de Servicios El Barzón, A.C. y el Movimiento Nacional El Barzón APN, provienen de la Confederación Nacional de Productores Agropecuarios y Forestales El Barzón. Además de estas "cabezas" nacionales, el barzonismo cuenta en su seno con una enorme multiplicidad de barzones regionales y locales que poseen una gran autonomía de acción, pero que en coyunturas específicas logran un nivel de visibilización pública coordinada bastante notable. este periodo histórico, en el agotamiento paulatino de la referencia al Estado (entidad en la que se transponía la trascendencia otrora divina) como respuesta meta-social a las problemáticas sociales (cf. Lechner, 1975). Enseguida percibimos el agotamiento aparentemente definitivo - más no por ello inmediato- del modelo nacional-popular de desarrollo, con el cual entran también en crisis formas específicas de coordinación social y, por tanto, expresiones concretas de acción social y política que, aunque implicaban posiciones opuestas entre sí, abrevaban de referentes que les eran comunes. Íntimamente ligado con lo anterior, vivimos la implantación salvaje del modelo neoliberal que, en el contexto de la globalización $y$ de la integración económica al TLC con Estados Unidos y Canadá en condiciones sumamente asimétricas para nuestro país, acelera la crisis del anterior modelo e impone nuevos rumbos con costos sociales significativamente elevados. Finalmente, encontramos el fenómeno de alternancia política que, con la derrota del candidato a la Presidencia de la República del Partido Revolucionario Institucional y el triunfo del abanderado del Partido Acción Nacional, Vicente Fox Quezada, en julio del 2000, representa la consumación parcial - bajo el signo del programa liberal — de un largo y accidentado proceso de transformaciones dentro de eso que se ha dado en llamar la transición democrática. Cada uno de estos cuatro procesos abre campos de acción $y$, por tanto de disputa entre los distintos actores sociales y políticos, que permiten distinguir analíticamente las distintas orientaciones en juego en dichas acciones y en la dinámica societal en su conjunto en este periodo histórico. Evidentemente, estas dinámicas están estrechamente vinculadas y se retroalimentan unas a otras, de tal forma que, distinguirlas de manera franca solamente es posible hacerlo a través de una operación de abstracción analítica.

Si la pretensión general expuesta es correcta, entonces podremos hablar de orientaciones de la acción social y política en el país de distinta naturaleza: a) a favor o en contra de la secularización de lo político, b) a favor o en contra del destronamiento del modelo nacionalpopular de desarrollo, c) a favor o en contra del predominio del modelo neoliberal, $y \mathrm{~d}$ ) a favor o en contra de la profundización de los procesos de 
transformación democrática ${ }^{2}$. La combinatoria entre los distintos ejes de acción y, por tanto, de conflictividad señalados (de todos o de algunos), $y$ la centralidad que alguno de ellos posea en cada caso concreto, expresarán la estructura de la mayoría de los actores del México actual. En otro sentido, las demandas efectuadas por los actores podrán situarse exclusiva o combinadamente, simultánea o alternadamente, en los planos —en clave touraineana - reivindicativo (de la redistribución de los recursos sociales), político (de la toma de decisiones de interés general) o de la historicidad (de los referentes axiológicos que dan sentido al conjunto de la producción social).

Hablando ya del barzonismo, propondremos aquí que se trata de una corriente de movilización social que se opone frontalmente a los efectos devastadores que la instauración del proyecto neoliberal ha tenido para los miembros de las capas medias rurales y urbanas, pero que rompe sólo parcialmente con las formas distintivas de los actores característicos del modelo nacional-popular. Se trata de una gran movilización - bastante heterogénea- que inició con la demanda de redistribución de los recursos sociales para salvar a los productores rurales afectados por la descapi-

2 En el primer caso, encontramos variantes favorables o contrarias a la expansión de los procesos de secularización, ya sea en términos de desestatización de lo social y lo político y/o en términos de laicización de la vida pública. En el caso de las posiciones opositoras al desmantelamiento del modelo nacional-popular, estas pueden ser de signo reactivo o reformador, mientras que entre las posiciones favorables aparecen las partidarias del programa neoliberal (ahora partidarias de una competitividad electoral efectiva más una liberalización plena de la economía) o aquellas que luchan por una democracia plena dentro de la política, pero también por la horizontalidad y complementareidad entre esta esfera y la sociedad civil. En el tercer caso podemos distinguir posiciones opositoras al neoliberalismo de signo reactivo, reformador o sustitutivo, $y$ posiciones favorables a la liberalización total o estratégicamente regulada de la vida económica, social y política en el contexto de la inserción en los mercados mundiales. En el último caso, las posiciones favorables a la democratización pueden referirse a la dimensión procedimental-electoral, al conjunto de la dinámica de la esfera política o bien pugnar por la extensión de la democracia al dominio de lo social. talización del campo, debido a la apertura comercial en condiciones desventajosas para los actores económicos nacionales pequeños $y$ medianos, $y$ a la crisis financiera sobrevenida a raíz del "error de diciembre" de 1994. Posteriormente, teniendo como telón de fondo la urbanización acelerada y definitiva de la movilización, el rumbo del conflicto con los bancos, primero, $y$ después también con el gobierno federal, condujo al más influyente de los actores del barzonismo - La Unión de Productores Agropecuarios, Industriales, Comerciantes y Prestadores de Servicios El Barzón A.C. (en lo sucesivo Barzón Unión) - a la decisión de diversificar su lucha accediendo a las contiendas político-electorales, buscando con ello incidir en el diseño de las políticas económicas federales. Paralelamente, el cuestionamiento ético al desempeño de los actores políticos partidistas, las modalidades novedosas de relación con el ámbito de la política — participación electoral pluri-partidista conservando como eje de su acción las demandas de los deudores elevadas a la condición de problemas públicos-, así como las significativas transformaciones en la subjetividad de muchos de sus miembros y el desarrollo de una cultura jurídica en amplias franjas de la población, permiten pensar en la incidencia de esta acción colectiva en el terreno de la historicidad - aunque este no constituya el centro de su accionar.

\section{TRANSICIÓN POLÍTICA Y NEOLIBERALISMO SALVAJE}

Mucho se ha escrito para definir el alcance de las transformaciones políticas que vive nuestro país: liberalización política, profundización de la democracia, transición a la democracia, etc., son algunas de las denominaciones con que este periodo ha sido descrito. Igualmente, la fecha de inicio y de conclusión de dicho proceso es también objeto de controversia. Algunos afirman que todo inició con el movimiento estudiantil de 1968; otros, que fue a partir de la reforma electoral de 1977, impulsada por Jesús Reyes Heroles ${ }^{3}$, 
otros más, que esto comenzó en la coyuntura del movimiento electoral cardenista de 1988 (alimentado por el despertar de los pobladores de la Ciudad de México debido a la tragedia de los sismos de 1985). Hay incluso algunos panistas que suponen que la transición dio inicio en el momento de la alternancia política del 2000. Por su parte, el término de tal transición estaría marcado, para algunos, por las Reformas político-electorales de 1996; para otros, por el triunfo perredista en la Ciudad de México en 1997 y, para otros más, por la alternancia en la presidencia de la República en el 2000. Muchos otros piensan que tal transición política no tendría asegurado, sino parcial y muy frágilmente, su condición de democrática, y que la conclusión de la misma no estaría aún, ni por mucho, a la vuelta de la esquina, argumentando para ello que alternancia no significa por sí misma transformación democrática de un régimen.

Retrocedamos un poco. Después de los trágicos acontecimientos del 2 de octubre de 1968, el movimiento social independiente en México siguió dos líneas principales de acción (Zermeño, 1997): la insurgencia sindical y la creación de partidos y organizaciones sociales marcadas por la consigna de ir al pueblo, entre los cuales Línea de Masas, de inspiración maoísta, alcanzó un predominio indiscutible con el tiempo. Posteriormente, en la coyuntura de la apertura política del 77 , concebida para responder a la oleada de acción colectiva propiciada por la liberalización echeverrista ${ }^{4}$ del régimen (1970-1976), múltiples organizaciones decidieron integrar frentes que les otorgaran capacidad de presión y mayor viabilidad política con miras a "alcanzar el poder político del Estado". Sin embargo, a la postre, esta incorporación política $y$, en algunos casos electoral, redundó, una vez más, en el vaciamiento de lo social y en la tendencia a la buropolitización de sus dirigentes (Zermeño). Ante esta tendencia general $y$, frente a la salida de las dictaduras en América Latina y a la crisis estrepitosa del socialismo real en Europa del Este, el discurso de la transición democrática ganó cada vez más terreno, colocándose

En referencia al periodo presidencial de Luis Echeverría Álvarez (1970-1976). en el centro de la agenda de la inmensa mayoría de los actores sociales y políticos, contribuyendo gradualmente con ello a la democratización de la dinámica electoral.

Paralelamente, con el agotamiento del modelo económico sustitutivo, el desencadenamiento de la crisis del petróleo en 1982 y la implantación abrupta y acelerada del proyecto neoliberal a partir de ese mismo año, un nuevo escenario social se dibujaba. Por un lado, vivimos la apertura desregulada de la economía nacional al mercado internacional, principalmente en el marco de la integración al GATT y al TLC; el viraje de la economía nacional hacia la dinámica maquiladora de exportación y su apuntalamiento en la dinámica financiera-especulativa que aportaba los capitales necesarios, pero volátiles, para mover al conjunto del aparato. Por otro lado, presenciamos una política de privatización desenfrenada de muchos de los sectores estratégicos del país (como la banca, las carreteras, la telefonía, etc.), de la mano de la disminución de la intervención estatal en el sector social. Los efectos combinados de estos procesos significaron la ruina de millones de pequeños, medianos $y$ hasta grandes empresarios, abrieron un abismo en el que se hundieron millones de miembros de las capas medias rurales $y$ urbanas, $y$ aumentaron aceleradamente el empobrecimiento de los sectores más desprotegidos. Este escenario produjo la estructura de oportunidades que habría de incubar el descontento que se expresaría paulatinamente en las urnas, fortaleciendo en pocos años a los partidos opositores y debilitando paradójicamente a los actores sociales llamados tradicionales (Olvera, 1999:355).

En ese contexto socioeconómico crítico, pero aparejado al discurso de la transición democrática que impulsaba el desmantelamiento de las bases autoritarias del modelo nacional-popular, muchas organizaciones emanadas de esa matriz de acción histórica debieron replegarse para sobrevivir, unas más lanzaron esfuerzos de refuncionalización, incorporándose a la oferta del Programa Nacional de Solidaridad salinista, y muchas simplemente desaparecieron. Sin embargo, dentro de ese panorama de relativo desdibujamiento de las organizaciones independientes, se multiplican $y$ adquieren gran auge ONG's $y$ asociaciones civiles de todo signo, vinculadas 
a los distintos rubros abiertos por el discurso de la transición democrática. También aparecen organizaciones como El Barzón, Alianza Cívica y el Ejército Zapatista de Liberación Nacional, las cuales inauguran un ciclo de reactivación de lucha social desde modalidades inéditas de organización y acción.

\section{LA ACCION COLECTIVA EN EL PERIODO DE TRANSICIÓN}

Al introducirnos al análisis de la acción colectiva en México en este periodo, encontramos posiciones sumamente diversas y hasta opuestas entre sí, que muestran en conjunto, la enorme complejidad de la realidad social de nuestro país y las dificultades para aprehenderla analíticamente. Así, en un extremo encontramos trabajos basados en la hipótesis de la descomposición creciente de lo social. Sobre esta línea de pensamiento, inspirada en la sociología de la decadencia, Sergio Zermeño (op.cit.) sostiene que la modernización salvaje que experimenta el país bajo el auge neoliberal produce la descomposición de su frágil modernidad, al desmantelar a los actores que podrían propiciar un desarrollo económico, social y político autónomo, sostenido y no estadocéntrico, y que serían capaces de impulsar el mejoramiento de las condiciones de vida y de participación de la población. El efecto socialmente desarticulador del neoliberalismo tiene que ver fundamentalmente con los efectos altamente perniciosos de la inserción del país en las dinámicas de apertura e integración económica en condiciones abismalmente asimétricas e insuficientemente reguladas, inserción acompañada de una acción deliberada por parte del Estado para destruir cualquier identidad colectiva consistente que pudiera representar un foco de resistencia frente a este proyecto. Estos factores vienen a añadirse, según Zermeño, al profundo desorden ocasionado por "el descontrol demográfico, del pasaje abrupto de lo tradicional a lo campesino a lo urbano, de la industrialización excluyente y de la crisis de estancamiento de los años ochenta" (Ibid:322). En su opinión, la presencia de acciones colectivas del tipo del EZLN, el Barzón, Alianza Cívica, así como de ONG's de distinto signo, y aún de la activa manifestación ciudadana en las calles, no puede ser interpretada como síntoma de embarnecimiento de lo social, pues estas modalidades intermitentes $y$ muchas veces fugaces de acción no trastocan significativamente el tipo de relación vertical entre Estado y sociedad. En sus propios términos:

... sería inocente confundir la imagen de las 100 marchas con la idea de fortalecimiento de la sociedad civil desde el momento en que detrás de esas manifestaciones no se está generando una intermediación institucional y organizativa ni, al menos en este momento, se están robusteciendo actores sociales con cierta continuidad en el tiempo (Ibid:327).

Es bajo este escenario que la población tiende a replegarse sobre sí misma a partir de identidades defensivas que catalizan la fragmentación de lo social y que contribuyen a la monopolización de lo público por el Estado. Todo lo anterior lleva a este autor a preguntarse: "¿dónde queda nuestro tránsito a la democracia, es decir, la capacidad de nuestros actores sociales para embarnecer, darse personalidad frente al Estado, frente al vértice de la pirámide?" (Ibid:333). Para él, contra el discurso optimista de la transitología, el regreso de los liderazgos autoritarios constituye la hipótesis más plausible en México $y$ en Latinoamérica como respuesta de la población ante la creciente y violenta descomposición del tejido social.

En el otro extremo del continuum analítico sobre el tema, tenemos las posiciones que, como en el caso de Alberto Olvera (1999), sostienen que la sociedad civil experimenta una paulatina consolidación. Partiendo de los desarrollos de Cohen y Arato a la visión habermasiana de sociedad civil, este autor asume dicho concepto, ya en clave sociológica, como el ámbito en el que se verifican, mediante prácticas comunicacionales orientadas fundamentalmente al consenso, los aprendizajes socioculturales normativos que permiten a la sociedad organizada auto-controlarse $y$ controlar institucionalmente el funcionamiento de los sistemas político y económico. En opinión suya, la sociedad civil mexicana se consolida gracias a: 
... la creación y estabilización de la esfera pública, al surgimiento y desarrollo de una red de asociaciones civiles, a la aparición y permanencia de diversos movimientos sociales y a la lenta construcción de una red de relaciones no clientelares $y$ no verticales entre actores sociales, actores e instituciones políticas y las instituciones y prácticas del mercado (Ibid:339).

De esta forma, la sociedad civil es comprendida, por un lado, como una dimensión institucional compuesta por el conjunto de derechos producidos por la modernidad que regulan la reproducción cultural, la integración social y la socialización, así como las relaciones entre Estado $y$ sociedad civil $y$ entre sociedad civil $y$ economía. Por otra parte, la sociedad civil es asumida como una dimensión práctica, toda vez que esta implica “... un conjunto de movimientos sociales, asociaciones civiles, grupos informales e individuos influyentes en la opinión pública cuya acción mantiene y amplía los horizontes de la autonomía social" (Ibid:343).

Este autor considera que todo ciclo de institucionalización democrática es precedido de un periodo de lucha sociocultural orientada por reconocimiento de nuevos derechos y a la constitución de nuevas identidades colectivas. En el caso mexicano, ese proceso desigual y gradual de institucionalización democrática se estaría verificando sobre una matriz sociocultural heterogénea y económicamente segmentada que da lugar a una combinación específica de "identidades y valores primordiales" al lado de otros modernos, produciendo así nuevas desigualdades en los niveles de conocimiento y poder disponibles para los diferentes actores sociales.

Históricamente, el agotamiento del modelo desarrollista del Estado mexicano (patrimonialista, corporativista y clientelar), debido en parte al reclamo democratizador-autonómico de los propios actores sociales y políticos, $y$ en parte a la crisis estructural iniciada en los años ochenta, dio lugar a las políticas neoliberales que permitieron, a través de las privatizaciones y el ingreso a la economía globalizada, la diferenciación creciente entre Estado y economía. Al mismo tiempo, el retiro del Estado de vastos sectores de lo social, ha estimulado la diferenciación entre Estado y sociedad, en la medida en que este abandono ha propiciado nuevos reclamos y ha hecho necesaria la activación autónoma de la acción social organizada para introducir sus reivindicaciones en la agenda público-política. Por otra parte, el agotamiento de la capacidad corporativista del anterior régimen generó las posibilidades para reavivar las expectativas sociales de cambio a través de una dinámica electoral que devenía competitiva, con lo que la diferenciación entre Estado, sistema de partidos y sociedad también avanzaba. En síntesis, la sociedad civil mexicana estaría emergiendo, lenta y problemáticamente, como una respuesta al agotamiento del viejo orden.

Por su parte Juan Manuel Ramírez y Jorge Regalado (1997), partiendo por distinguir los actores corporativos de los independientes y los tradicionales de los modernos, elaboran una cartografía más compleja y sistemática del universo de la acción colectiva en México. Los autores perciben en dicho universo tres tendencias fundamentales: "a) el reflujo de la mayoría de los actores sociales tradicionales, independientes y corporativizados; b) la refuncionalización de una parte de ambos, $y$ c) el surgimiento de otros nuevos" (Ibid:15). Las características propias de los nuevos actores serían, en su opinión, la mayor flexibilidad organizacional y la combinación de demandas de naturaleza reivindicativa y sectorial con otras de índole política y a veces cultural.

Según su punto de vista, la crisis de los actores tradicionales tuvo lugar a mediados de los años ochenta, cuando la política social del régimen se tornó compensatoria de los efectos del neoliberalismo salvaje, dirigiéndose a los estratos más marginados de la población (ver el caso del Pronasol), lo que implicó el abandono de los segmentos anteriormente privilegiados $y$, por tanto, el socavamiento de la capacidad de representación de intereses de sus organismos gremiales. Los actores tradicionales independientes no fueron sin embargo capaces de capitalizar esta circunstancia, siendo algunos de ellos atraídos por la oferta asistencialista del régimen, mientras que otros intentaron sin éxito insertarse en la vida electoral, con lo que se agudizó la descomposición de este sector de acción organizada. Entre los actores que sí pudieron 
refuncionalizarse se cuentan los pertenecientes a los sectores de profesionistas, empresarios $y$ fuerzas armadas, quienes por su mayor nivel educativo y el mayor flujo de información de los que disponen, fueron capaces de ajustarse a las realidades emergentes.

Entre los nuevos actores, Ramírez y Regalado detectan dos sectores principales: aquellos provenientes de los grupos de los años setenta (estudiantiles, minorías sexuales, ecologistas, mujeres, juveniles, culturales, de la tercera edad, los pertenecientes al MUP, a las comunidades eclesiales de base y las ONG's) y los que surgen en los noventa: Alianza Cívica, El Ejército Zapatista de Liberación Nacional y El Barzón. En lo tocante al importante auge de las ONG's, este se explicaría por el favorable contexto de aplicación, por parte del Estado, de programas de asistencia social, desarrollo y promoción, así como por el crecimiento de la lucha por la defensa de los derechos humanos y de la educación cívica. Adicionalmente, las ONG's estarían fungiendo como fuente de empleo para porciones considerables de las capas medias que, siendo politizadas, profesionalizadas $y$, muchas veces opositoras al gobierno, han desarrollado una capacidad importante para incidir en los asuntos de orden público. Por su parte, los actores de los noventas tienen como rasgo común haber cuestionado en su conjunto al modelo económico y político vigente, haber implementado formas de organización más directas, plurales y flexibles, $y$ haber producido una simbólica de lucha renovada que ha repercutido en forma importante en la captación del apoyo ciudadano.

Muchas son las reivindicaciones de estos tres tipos de actores detectadas por los dos autores. De los actores tradicionales refuncionalizados, destacan la demanda de nuevas formas de organización, representación gremial y relación con el gobierno, $y$ la reducción de las desigualdades sociales. De los actores independientes renovados, la exigencia de relaciones más respetuosas entre Estado y organizaciones sociales, así como el reconocimiento a la diferencia y la pluralidad. De los nuevos actores, la lucha por la creación y ampliación de espacios públicos para la participación social, el mayor acceso de los ciudadanos a la información, la vigilancia ciudadana sobre los gobernantes y la transformación de la concepción del ejercicio del poder como un servicio a cumplir frente a la sociedad. Todos estos actores compartirían además el interés por el establecimiento del Estado de Derecho y por la democratización del régimen (aunque en grados distintos).

En lo referente al signo de la transición política en el país, todos los autores citados hasta aquí conciben como insuficiente la modificación del marco electoral-partidista para hablar de transición democrática $y$, si bien la consideran importante, afirman que es además indispensable la expansión de la democratización al ámbito de lo social. Además, la presencia de enclaves autoritarios $^{5}$ (Garretón, 2001) en el régimen y la sociedad, y el signo elitista e impopular de la actuación del Estado, impiden hablar de la constitución de una democracia en México, entendida como un orden político capaz de generar orden social (Aguilar, 2001), ya que, por el contrario, este produce aceleradamente desorden a través del proyecto de país que impulsa.

\section{EJES ARTICULADORES \\ DE LA ACCIÓN COLECTIVA EN MÉXICO}

A continuación intentaré decantar algunas de las características apreciables empíricamente en el universo de los actores existentes en el país que han tenido una mayor influencia durante los últimos años. Evidentemente, los actores podrán poseer uno o varios de estos rasgos distintivos $y$, desde luego, la novedad de algunos de estos atributos no borrará la coexistencia y la tensión, en el seno de una misma acción colectiva, con otros atributos socialmente pre-existentes o llamados "tradicionales".

En primer término, podríamos pensar, en un nivel axiológico, en la disputa por los contenidos a otorgarse a la noción y a la práctica de la

$5 \quad$ Para Garretón, los enclaves autoritarios son “... los elementos que por definición pertenecen a un régimen autoritario, autocrático, militar o democrático-excluyente, y que perduran en el régimen democrático que le sucede, impidiendo que se transforme en democracia política plena" (2001:60). Los enclaves autoritarios pueden ser de tipo institucional, ético-simbólico, actorales y culturales. 
democracia, esto es, por los significados concretos a atribuirse a ciertos referentes discursivos (narrativos y prácticos) que se consolidan aceleradamente como universales capaces de regular la coordinación de la acción social y política en el nuevo contexto. En este mismo terreno, habría que señalar la importancia del proceso de "institucionalización democrática" (cf. Ramírez, 2000), el cual abre un campo de interacción sociopolítica significativamente importante, en la medida en que de él depende la definición de los marcos normativos concretos que habrán de regir la resolución de los problemas públicos que atañen a los distintos actores.

Otro aspecto importante a destacar, ahora en el registro de la cultura política, es la reivindicación defensiva del imaginario nacional-popular. A contramano del discurso de la democratización de la vida política enarbolado por muchos de los actores consolidados dentro del anterior modelo de relación Estado-Sociedad (caracterizado por el hiper-presidencialismo, la existencia de un partido de Estado y una inclusión corporativizada de la sociedad a la vida nacional), al ver desestructurados los ejes de la coordinación social y política con base en los cuales funcionaban, o al ver en desuso los referentes que regulaban su interacción conflictiva con el Estado y con otros actores, enfrentan el reto de recomponerse o de intentar reconstituir dichas pautas que sirven para procesar la contingencia múltiple implicada por su acción. Por lo profundamente arraigado de la cultura política nacional-popular, por lo joven del proceso de democratización y por el auge de la noción procedimental-elitista de la transición política, la aparición de una cultura democrática que enmarque de manera sustancialmente distinta las prácticas sociales y políticas aún está en estado germinal en México. Esto propicia que muchos actores se vean desposeídos de formulaciones axiológicas $y$ prácticas $y$ de las herramientas necesarias y suficientes para romper de manera definitiva con el referente del anterior modelo, situación que los lleva a proclamar la necesidad del retorno a lo conocido o de su refuncionalización, pero sin trastocar sus contenidos fundamentales.

Por otro lado, la proclama de retornar al modelo-nacional popular se mezcla, en ocasiones hasta confundirse, con las posiciones antimundialización (es aún el lado defensivo de esta lucha el que prevalece en México, con excepciones notabilísimas como en el caso del zapatismo), enjeu este último, que muy lentamente adquiere importancia en el horizonte de la lucha social y política en el país.

En lo concerniente a los componentes sociales de las movilizaciones recientes, se aprecia una articulación de carácter predominantemente post-clasista. No se trata de que ya no existan actores clasistas o de que no intervenga el factor de clase en los procesos de constitución, funcionamiento y reproducción de la acción colectiva. Sin duda opera en ella para generar diferenciaciones internas y para imprimir ciertas condicionantes a la acción. Sin embargo, la clase no es, actualmente, el eje fundamental para definir la naturaleza de los conflictos más relevantes, ni para articular los universos de agraviados a quienes interpelar para movilizarse, ni para definir a los adversarios en cuestión. Claramente se percibe la sustitución de esos referentes por otros de naturaleza "funcional" (consumidores, productores, ahorradores, deudores, electores, etc.) o identitaria (condición genérica, étnica, etárea, etc.), observando frecuentemente una composición pluriclasista en las movilizaciones concretas.

Si por un lado la diferencia de clase se cuela en las acciones colectivas sin que estas puedan aún procesarla de forma suficientemente creativa, el derecho y el reconocimiento a la diferencia se ha erigido por otros actores en una bandera fundamental en sí misma. La diferencia se erige así cada vez más en uno de los referentes más defendidos y al mismo tiempo más controvertidos que da lugar a múltiples debates $y$ a proclamas por parte de la casi totalidad de los actores políticos, incluido el mismo Estado. Sin duda, la posición más avanzada en este debate defiende la necesidad de articular el derecho a la diferencia con la vigencia de principios universales que sienten las bases para la vida de todos en común; dicho en términos zapatistas: se trataría en este punto de crear "un mundo donde quepan muchos mundos". Siendo uno de los ejes de la agenda democrática nacional, esta demanda no ha tenido sin embargo una traducción institucionalizada que se revele efectiva en la vida del país.

La lucha por la ampliación institucionalizada de lo público, y la definición y defensa de los 
derechos individuales $y$ de grupo ${ }^{6}$ como derechos ciudadanos, representa uno de los filones más consistentes que estimulan la acción social de los últimos tiempos. Correlativamente, los límites de lo privado son también tendencialmente redefinidos. En todos esos casos asistimos a esfuerzos múltiples por ensanchar el ámbito de lo público, sobre la base de prácticas comunicativas entre los actores $y$ de la institucionalización de sus posibilidades de participación, así como por democratizar y volver más igualitarias y equitativas las interacciones en el ámbito privado ${ }^{7}$. De manera transversal a este esfuerzo de redefinición de las fronteras y de la estructura de lo público y lo privado, asistimos a la expansión del trabajo de los actores involucrados, del ámbito de lo local-nacional al de lo internacional. Al mismo instante que la apelación a lo universal constituye una estrategia discursivo-política con fuerza creciente, acudir a las instancias jurídicas y a la opinión pública internacionales como parte de la ruta crítica de la acción social, es también un signo cada vez más persistente en esta época.

Otro aspecto fundamental es la lucha por el control público de la información. Desde el trabajo de recuperación y divulgación de informaciones manejadas de manera absolutamente discrecional $y$ en beneficio propio por los actores políticos, fundamentalmente por las distintas instancias del Estado, un número creciente de organizaciones y movimientos han logrado romper con el monopolio en este crucial renglón. Aumentan con ello su margen de maniobra, cuestionan la moralidad $y$ hasta la legalidad de ciertas prácticas de los actores políticos, obligándolos en ocasiones a dar explicaciones de sus actos ante la ciudadanía y, creando con todo ello, las condiciones para transparentar gradualmente la vida política. En ocasiones, esta disputa por el control

6 En la defensa de lo particular como ámbito de derechos con la misma legitimidad que lo universal, radica el aporte de la experiencia mexicana (ver como caso paradigmático la lucha del zapatismo) y latinoamericana frente al universalismo abstracto del republicanismo europeo, para el cual el individuo debe despojarse de cualquier particularidad de grupo a fin de poderse integrar a la nación (cf. De Grammont: 2001).

$7 \quad$ Los dos ejes de la noción de "mundo de vida" en Arato y Cohen (cf. Olvera, op.cit.:342). público de la información se presenta en sectores de la vida nacional donde la misma posee un papel crucial, tal como en el caso del sector financiero (ver por ejemplo, el problema de las listas secretas de los créditos absorbidos - en muchos casos de forma ilegal- por el Fondo Bancario de Protección al Ahorro, y que fueron hechas públicas por los dirigentes de El Barzón Unión).

Un último elemento a remarcar en el universo de la acción colectiva reciente en el país (y en todo el continente) es la centralidad creciente que adquieren los conflictos de naturaleza financiera. Más allá del peso de esta actividad respecto del conjunto de la dinámica económica, numerosos segmentos de la población inmersos en este sector, en calidad de deudores y ahorradores, se han movilizado generando acciones tan poderosas y con tanto impacto mediático y político, que han obligado al mismo poder ejecutivo federal, así como al organismo cúpula de los banqueros, a responder con programas de solución — nunca de fondo, pero políticamente efectivos- en reiteradas ocasiones. Estas movilizaciones sociales además han mostrado la preocupante fragilidad de este rubro medular de la vida nacional, inaugurando al mismo tiempo un campo de lucha que sin duda crecerá en importancia política, dadas las implicaciones del funcionamiento de este sector para el conjunto de la dinámica económica en nuestro país y en el mundo y, dados los descalabros mayúsculos que, como en nuestro país, en Argentina $y$ otras naciones sudamericanas, este enfrenta en los años recientes. Además, estas expresiones de lucha de paso han puesto al descubierto la franca inmoralidad de la lógica especulativa con que muchos de los agentes privados $y$ estatales de mayor peso operan, así como el enorme costo social que este accionar trae consigo.

\section{LOS DEUDORES MEXICANOS ENTRE LA TRANSICIÓN Y EL NEOLIBERALISMO}

Hablemos ahora del barzonismo ${ }^{8}$. El barzonismo es una gran corriente de movilización

8 El barzón es el anillo de hierro, madera o cuero por donde pasa el timón del arado en el yugo. El barzón es también el nombre de una canción popular que evoca al México pre-revolucionario, y que habla de la situación de explotación trans-generacional 
social nacida en agosto de 1993 en el estado de Jalisco $^{9}$, y poco tiempo después en Zacatecas ${ }^{10}$, que toca sectores diversos de las clases medias del campo ${ }^{11}$ y la ciudad, sujetos de crédito, que se encontraron intempestivamente ante la imposibilidad de pagar los adeudos contraídos con los bancos y los agiotistas $y$, por tanto, ante el riesgo de perder los bienes ofrecidos como garantía ante sus acreedores. Hay que destacar que se trataba básicamente de sectores productivos $y$ de servicios que, confiando en la promesa gubernamental del inminente ingreso de México a las filas del Primer Mundo, apostaron fuertemente a su propia modernización, a fin de afrontar adecuadamente los retos de la apertura económi$\mathrm{ca}^{12}$. En otros casos, aunque un poco más tarde, se trató de sectores que hicieron adquisiciones

a que eran sometidos los peones arraigados a las haciendas, a través del mecanismo de las tiendas de raya. En estas, el peón recibía los medios apenas indispensables para su sobrevivencia a precios imposibles de cubrir, lo que le implicaba seguir trabajando para el señor hacendado sin poder nunca solventar la deuda, por lo que la misma se heredaba a los hijos, reproduciendo con ello el vínculo de explotación.

El movimiento en Jalisco estuvo compuesto inicialmente por pequeños y grandes propietarios agrícolas privados, $y$ disponía del apoyo de personalidades sobresalientes del PRI y el PAN locales, así como de sectores de la iglesia católica en el Estado.

10 El Barzón en Zacatecas estaba originalmente compuesto sobre todo por ejidatarios y pequeños propietarios. Sus apoyos provenían fundamentalmente del PRD, $y$ en un primer momento, también del PRI.

11 El universo original de deudores implicados en la crisis de carteras vencidas incluía grandes empresarios agrícolas privados (entre los cuales se contaba un sector agro-exportador moderno), "rancheros" y ejidatarios medios con orientación transicional.

12 En este punto, es muy elocuente la proporción de deuda acumulada por la banca comercial: $62 \%$, que correspondía al $27 \%$ de los deudores; mientras que la banca de desarrollo acumulaba el $38 \%$ de la deuda restante, correspondiente al $73 \%$ de los productores. La media de las deudas con la banca comercial ascendía a 197558 pesos, mientras que con la banca de desarrollo, a 38796 pesos (De Grammont, 2001). inmobiliarias (casas-habitaciones) y mobiliarias (vehículos), confiando en que la salud de la economía les permitiría reabsorber los costos de sus compromisos sin mayor problema. Esta disposición al endeudamiento estuvo además estimulada por el desmesurado otorgamiento de créditos por parte de la banca, así como por la circulación excesiva de dinero plástico, lo que ocasionó asimismo la posterior bancarrota de un importante número de tarjeta-habientes. De esta forma, podemos afirmar en términos globales que El Barzón nace como una movilización de defensa del patrimonio familiar de los productores arruinados, a la vez por los efectos que por las promesas de la política económica neoliberal del Estado Mexicano.

El sector rural, que fue la cuna de la movilización en el norte (Chihuahua, Sonora y Zacatecas) y el occidente (Jalisco) del país, vivía desde hacía bastante tiempo un proceso de constante descapitalización a raíz de la escasez y el encarecimiento de créditos $^{13}$, la disminución de subsidios $y$ de precios de garantía, $y$ la apertura no regulada de las fronteras nacionales a los productos provenientes de los vecinos del norte, aún antes de la entrada en vigor del TLC. A todo esto se añadían, por si fuera poco, severos fenómenos meteorológicos (sequías, inundaciones, granizadas, etc.) que se sucedían rápidamente y que dañaban en cada ocasión vastas extensiones de tierra cultivada. En ese contexto, y gracias a la existencia de importantes experiencias de movilización independiente en los estados arriba mencionados, estimuladas por la crisis del corporativismo en el sector rural (debido a su agotamiento como modo de representación de intereses en un contexto neoliberal en el que aquél devenía obsoleto en su configuración tradicional), la irrupción de los deudores se presentó con gran efervescencia en este sector.

En muy breve lapso, los deudores movilizados en los diferentes estados del país entraron en contacto $y$ pusieron en marcha las primeras acciones de gran envergadura. Es así que el 4 de

Siguiendo esa tónica, en el periodo 1994-2000 se observó la caída del crédito en un $80 \%$, así como la elevación de las tasas de interés del 15 al 160\% (cf. Ramírez, 2000). 
septiembre de 1993 tuvo lugar su primera asamblea nacional, en Guadalajara, Jalisco, a la cual asistieron cerca de 800 productores provenientes de 12 de las 32 entidades federativas del país. Las resoluciones fundamentales de dicha asamblea fueron crear una organización independiente y luchar juntos por la reestructuración de los adeudos caídos en cartera vencida. Al cabo de dos asambleas nacionales más, en las cuales su pliego petitorio y su programa de acción evolucionaban, $y$ después de algunas respuestas parciales al problema por parte del Gobierno Federal (el Programa de Apoyo al Campo y el Programa de Saneamiento Financiero y Técnico del Sector Agropecuario) y de los bancos (programas de reestructuración de los adeudos), el 17 de noviembre nace por fin la Confederación Nacional de Productores Agrícolas y Forestales El Barzón, nombrando como su presidente a Maximiano Barbosa Llamas. Apenas pasados cuatro meses de las primeras movilizaciones, los barzonistas decidieron realizar una marcha hacia la Ciudad de México, que daría inicio el 20 de noviembre y que habría de movilizar a contingentes (con un importante número de tractores) provenientes de distintos estados del país, sobre todo de Jalisco, Colima, Nayarit, Michoacán, Guanajuato, Aguascalientes y Zacatecas. Al mismo tiempo, deudores de Chihuahua bloqueaban los puentes fronterizos de Ciudad Juárez en protesta por las repercusiones económicas de la entrada en vigor del TLC. Sin embargo, el 23 de ese mes, los principales dirigentes (Maximiano Barbosa y Héctor Madera en Jalisco; y Juan José Quirino, Manuel Ortega, Pedro Rodríguez y José Nieves, en Zacatecas) fueron apresados y conducidos al Penal de Puente Grande, en Jalisco. Debido a la presión de los deudores, de múltiples organizaciones campesinas (como la Unión Nacional de Trabajadores Agrícolas, la Central Independiente de Obreros Agrícolas y Campesinos, la Coordinadora Nacional Plan de Ayala, la Coordinación Nacional de Pueblos Indígenas, etc.) y a la de múltiples personalidades políticas nacionales de distinta filiación, así como religiosas, los dirigentes fueron liberados en pocos días.

A pesar del origen rural de la movilización, muy rápidamente algunos de los líderes barzonistas percibieron la magnitud de la crisis de carteras vencidas y decidieron pugnar por la urbanización de su acción ${ }^{14}$, razón, entre otras, que catalizó la escisión entre las dos principales corrientes al interior de la naciente organización. Es así que el grupo confrontado a Maximiano Barbosa, encabezado por Quirino Salas, Manuel Ortega, Alfonso Ramírez y Liliana Flores ${ }^{15}$ (todos de filiación perredista), funda el 13 de octubre de 1994 en la Ciudad de Monterrey, Nuevo León, El Barzón Unión. Esta ala disidente era proclive a la urbanización y pluralización sectorial de la organización, a la representación de todos los estados en el órgano de dirección nacional, al carácter pluripartidista de la membresía y al mantenimiento de una actitud de fuerza en las relaciones con el Gobierno Federal y la banca. El curso de los acontecimientos habrían de dar la razón a estos dirigentes, ya que a partir del fatídico "error de diciembre" de 1994, el sistema financiero nacional entró en una crisis que se manifestó en la severa desestabilización del peso, debido a la decisión gubernamental de permitir la libre flotación de la tasa de cambio, ocasionando un rápido y estratosférico aumento de las tasas de interés bancarias a fin de retener los capitales golondrinos aposentados en el país. El costo que esto tuvo para los deudores ${ }^{16}$ en situación de cartera vencida de paso -incluidos en gran número los deudores urbanos-fue devastador ${ }^{17}$. Aunado a esto,

Entrevista con Liliana Flores Benavides, dirigente del Barzón en Nuevo León y Secretaria Nacional de Organización. Monterrey, Nuevo León, 19-sept. 2002 .

Los tres primeros provenientes del estado de Zacatecas y la última del de Nuevo León.

16 Se estima que para 1995, el número de deudores ascendía a ocho millones. Para 1998, la cifra ascendía a alrededor de 11 millones. Si incluimos en el cálculo al total de miembros de las familias implicadas y a los trabajadores empleados en sus negocios, la cifra asciende entonces a un nivel espectacular (cfr. Cartón, 2001).

Esto permitió una transformación radical de la membresía barzonista. Así, en 1994 se calculaban que cerca del $80 \%$ de los afiliados eran deudores urbanos: jefes de pequeñas y medianas empresas, comerciantes, tarjetahabientes, productores de masa para tortillas, transportistas, deudores hipotecarios, artistas. Otro dato relevante fue la participación, para ese mismo año, de alrededor de 300 mil mujeres (Torres, 1997). 
la práctica de la capitalización de los intereses por parte de los bancos alimentó el crecimiento exponencial de los adeudos en poco tiempo.

Desde su nacimiento, El Barzón Unión habría de convertirse en la punta de lanza que alcanzaría una mayor repercusión pública-mediática, y que jalaría tras de sí al conjunto del barzonismo otorgándole al mismo tiempo una cobertura política importante ${ }^{18}$. En términos globales, El Barzón Unión ha vivido hasta la fecha cuatro fases principales: la primera fue la de articulación organizacional y nacionalización de la movilización, que abarca el periodo de las primeras movilizaciones en las calles y ante las oficinas bancarias y Palacios locales y federales para solicitar la moratoria de pagos. En las primeras acciones de lucha, el lema enarbolado era "debo, no niego; pago, no tengo". Cabe destacar que en ese momento, las instancias gubernamentales aparecían aún como las posibles mediadoras en las negociaciones con los banqueros.

Otras de las demandas fundamentales en esta primera fase fueron: igualar las condiciones productivas de los productores en cartera vencida con las de sus competidores extranjeros a través de políticas de crédito y de subsidios; obtener apoyo oficial para crear organismos autónomos de productores con canales de comercialización adecuados y para poder participar en la toma de decisiones concernientes a la política agrícola. Igualmente, los barzonistas demandaban el cese de las acciones judiciales contra los deudores, la reestructuración de las deudas para todos los productores, la devolución de los bienes adjudicados, la prohibición de contratos judiciales $y$ la creación de un fideicomiso que absorbiera la parte recapitalizada de las deudas. Este periodo comprendió los primeros meses de 1993 y culminó con la división entre los partidarios de Quirino Salas y los de Maximiano Barbosa.

La segunda fase fue la de la urbanización de la movilización, y estuvo regida por la estra-

18 Las líneas estratégicas de trabajo que la organización desarrolla, $y$ que le han permitido adquirir tal capacidad de acción son: asesoría financiera, fiscal y contable, asesoría y coordinación productiva, asesoría social y de gestión, asesoría psicológica, desobediencia civil y realización de diplomados. tegia de lucha jurídica (que tuvo su auge hasta 1996, aproximadamente), por la que los deudores organizados reconocían la legitimidad de sus adeudos originales, pero exigiendo que había que pagar sólo lo que fuera justo (el lema que se acuñó fue entonces: "debo, no niego; pago lo justo"). En la puesta en práctica de esta nueva estrategia fue fundamental la alianza con la Barra Nacional de Abogados, que aportaba asesoría profesional a los deudores. Igualmente, la instrumentación de acciones de resistencia civil pacífica orientadas a la defensa de los bienes, pero también a la alteración del funcionamiento normal de las instituciones bancarias y de dependencias gubernamentales estatales $y$ federales, fueron el sello distintivo del accionar barzonista durante esos años.

Pasando al estatuto de pagadores ante los tribunales, $y$ luchando por desmontar el estigma que los bancos, el gobierno y muchos medios de comunicación les habían endilgado ante la opinión pública, llamándoles agentes económicos incompetentes y renuentes al cumplimiento de sus compromisos, los barzonistas pasaron a una iniciativa masiva de pago ante los tribunales $y$ de contra-demanda a muchas de las instituciones bancarias $y$ a los agiotistas ${ }^{19}$. El objetivo aquí era bloquear o entorpecer el funcionamiento del sistema judicial, claramente a favor de los banqueros, para ganar tiempo y poder así reunir los fondos para pagar sin quedar en la ruina. Ahora, las instancias de gobierno eran visualizadas como formando parte del problema y no de la solución, asumiendo que estas defendían activamente los intereses de los banqueros. Durante esta etapa, dio inicio la sectorialización de la organización que dio origen a barzones empresariales, de transportistas, de agroproductores, de artistas, de productores de masa para tortillas, etc., $y$ se sentaron también las bases de la internacionalización del esfuerzo de resistencia de los deudores, iniciando encuentros con deudores de otros países con miras a la creación del Barzón

19

Una estrategia central en el periodo fue cuestionar la existencia jurídica de los bancos creados fuera del plazo legalmente establecido para tal efecto en el marco de la reprivatización bancaria y, por tanto, cuestionar la legalidad de las deudas contraídas con ellos. 
Latinoamericano, bajo el argumento de que los verdaderos responsables del quebranto productivo $y$ financiero de nuestros países eran el FMI $y$ el BM. Este periodo estuvo también marcado por la firma del Pacto de Intocabilidad con el EZLN, con el que ambas organizaciones se garantizaba reconocimiento y apoyo mutuo ante una eventual agresión gubernamental, gestándose así una alianza estratégica con implicaciones simbólicas bastante relevantes: de nueva cuenta los alzados que vinieron del norte se encontrarían con los insurrectos del sur. Esta alianza, sin embargo, no habría de desarrollarse significativamente en términos programáticos en los años subsecuentes.

En esta fase, la defensa de la Patria y del patrimonio de las familias de los productores en cartera vencida representaba la consigna primordial de El Barzón ${ }^{20}$. Para ello, exigían un decreto de ley que obligara a renegociar la deuda externa, a suspender temporalmente los juicios mercantiles contra los deudores, a castigar el anatocismo (el cobro de intereses sobre intereses) y a limitar los márgenes de la intermediación financiera. Igualmente, dicho decreto permitiría instrumentar una amnistía fiscal a las empresas sin posibilidades de pago, así como poner en práctica una política tributaria equitativa, convertir la banca de fomento en banca de primer piso y crear un fideicomiso para reestructurar las carteras vencidas. Este decreto permitiría también proteger una serie de productos y sectores vulnerables de cara a la entrada en vigor del TLC. Por último, dicha iniciativa estaría destinada a reorientar el gasto público en inversión social con el propósito de generar empleos y establecer una política monetaria que asegurara liquidez a la economía nacional.

La tercera fase estuvo marcada por la participación electoral. Debido a la cerrazón de los banqueros, pero también del Estado, ante las propuestas de los deudores organizados, orientadas a compartir la responsabilidad entre las tres partes, estos últimos no tuvieron más remedio que intentar modificar la correlación de fuerzas en el conflicto, insertándose en la dinámica le-

20 Ver la "Declaración de Guadalajara" emitida por el Consejo Nacional del Barzón (20 de agosto de 1995). gislativa, desde donde, a su parecer, habrían de emanar las propuestas viables de solución al problema. En este periodo iniciado en 1996-1997, El Barzón Unión optó por una estrategia de alianza pluripartidista para enfrentarse al PRI-Gobierno. Sin embargo, claramente predominó el vínculo establecido con el PRD. Si bien esta estrategia permitió a los barzonistas alcanzar puestos de representación popular a niveles local y federal (destacan sobre todo el desempeño en la Diputación Federal de Alfonso Ramírez y de Quirino Salas en el Senado de la República), que les permitieron elevar su problema al estatuto de problema público e, incluso convertirlo en uno de los ejes de la agenda nacional durante mucho tiempo, los costos que esta apuesta implicó fueron bastante elevados. Muchos de los miembros, inconformes por la politización y la perredización de la movilización, manifestaron su desacuerdo $y$ hasta se escindieron, dando lugar a organizaciones como el Movimiento Jurídico Nacional y a la Alianza Nacional El Barzón. Por otro lado, el descuido de la actividad de la organización por parte de los cuadros dirigentes involucrados en la dinámica política partidista, propició el consecuente debilitamiento de la comunicación en su interior $y$ distrajo temporalmente el diseño y la instrumentación, hasta entonces sumamente creativa y eficaz, de su programa de acción. Este vaciamiento hacia arriba se concatenó con la gradual, sectorializada, y seguramente temporal, desactivación de la crisis de las carteras vencidas. Ambos factores repercutieron en la considerable disminución de la membresía y de la capacidad de acción barzonista a partir de 1998, a pesar de que las condiciones productivas de los diferentes sectores afectados no mejoraron, sino por el contrario, siguieron en continuo deterioro.

La cuarta fase inicia en julio del 2000, con la derrota electoral del Partido de la Revolución Democrática (PRD) y, por tanto, de su aliado, El Barzón Unión, hecho que obligó y permitió a los deudores reorientar su trabajo sobre sí mismos. En la medida en que no disponían ya de voces propias en el Congreso de la Unión y, debido a desacuerdos con la forma de proceder de ciertos dirigentes del PRD, los barzonistas se plantearon entonces la necesidad de redefinir su posición estratégica. Con la pretensión de responder al vacío político que desde la izquierda se apreciaba, han 
intentado desde entonces producir un polo que aglutine a las fuerzas sociales y políticas progresistas para, en un primer momento, garantizar la profundización de la transición democrática en el país, empujando al recién electo Presidente Fox a romper definitivamente con el anterior régimen. Sin embargo, ante el rumbo adquirido por los acontecimientos, que indican la continuidad, en lo fundamental, entre el priismo y el foxismo, los barzonistas pretenden crear ahora un frente de resistencia nacional a las reformas estructurales orientadas a modificar la legislación laboral, a privatizar el sector energético (petróleos y electricidad) y a sacar adelante una reforma fiscal de sello impopular al que se transferirían los costos del intento fallido de aumentar el IVA en medicinas y alimentos. Además, los barzonistas mantienen la exigencia de crear una Comisión de la Verdad que analice y resuelva lo conducente en el caso de los grandes quebrantos a la nación que han implicado, primero, la absorción de las carteras vencidas de los bancos por el Fondo Bancario de Protección al Ahorro (FOBAPROA), sin la depuración de las enormes operaciones fraudulentas que estaban ahí incluidas $y$, después, la posterior disolución de este fondo para volver públicos esos adeudos y administrarlos a través del después creado Instituto Bancario de Protección al Ahorro (IPAB).

Por último, habrá que señalar la iniciativa de El Barzón, junto con deudores venezolanos y colombianos y con ahorradores argentinos, por impulsar, en marzo del 2002, en Monterrey, Nuevo León, el proceso que presuntamente habría de desembocar en la creación de una confederación latinoamericana en defensa del patrimonio nacional $y$ familiar, prometedora iniciativa que colocaba al barzonismo en la vanguardia de la lucha social en el corazón mismo del modelo neoliberal a un nivel mundial: el sector financiero. Los principales acuerdos emanados de la reunión de Monterrey fueron ${ }^{21}$ : a) crear una red de solidaridad continental que aglutine a las organizaciones del Sub-Continente que defienden los patrimonios familiares, comunitarios y nacionales de las prácticas de especulación y usura

Cf. El documento "Compromiso de Monterrey" (12 de marzo del 2002). llevadas a cabo por las instituciones financieras; b) proponer medidas de acción social y jurídica contra los remates, exacciones, ejecuciones, intimidaciones y liquidaciones de deudas que hayan sido sobredimensionadas, impulsando al mismo tiempo modalidades de liquidación de las mismas sobre bases justas y razonables; c) luchar por la suspensión y renegociación del pago de las deudas externa e interna en cada país, destinando los recursos liberados a fondos nacionales de reparación productiva; d) luchar por la instauración de un impuesto sobre todas las transacciones financieras especulativas en el mundo (Tasa Tobin), destinando los recursos captados a los fondos de reparación productiva; e) participar en el control de los bancos centrales o superintendencias de actividades bancarias en cada país; f) promover legislaciones que obliguen a los bancos a dedicar parte de su cartera de préstamos a financiar proyectos, obras o servicios en beneficio del desarrollo familiar o comunitario; g) demandar el respeto irrestricto a los ahorros en manos de la intermediación bancaria; h) exigir que se respeten las disposiciones constitucionales y jurídicas concretas que consagran los derechos de los deudores financieros; i) reclamar la inclusión de las organizaciones integrantes de la Confederación en la planificación e implementación de programas financieros y productivos en cada país. Aunque la realización de este programa general aún está en una fase embrionaria y sus resultados son sin duda inciertos, la trascendencia del mismo en el actual contexto de globalización $y$ de predominio del capital financiero en el mundo, puede ser considerable de cara a la eventual producción de nuevas expresiones de acción social y política en la región.

Hoy, El Barzón Unión enfrenta una dinámica multidireccional sumamente interesante: en ciertos estados vive un procesos de aguda descomposición (v.g. Zacatecas), en otros se ha convertido en partido político local (v.g. Sinaloa), en otros más, desarrolla importantes proyectos productivos (v.g. Chiapas), y en otros se ha constituido en un referente fundamental de la lucha social y política local (v.g. Nuevo León). También de entre los contingentes escindidos del barzonismo por diferencias políticas, algunos de ellos comienzan a esbozar proyectos sociales $y$ productivos de nuevo tipo, lo que constituiría 
una modalidad más de activación social emanada de la matriz barzonista. Globalmente, tal como lo asumen sus dirigentes, El Barzón vive los efectos paradójicos de su éxito: mientras más cerca está la solución global del problema de las carteras vencidas, más se enfrentan a la desmovilización en sus bases. Por ello, esta acción colectiva se plantea el reto de experimentar una mutación tal que le permita reconfigurarse como fuerza social efectivamente autónoma, que impulse planteamientos programáticos innovadores en el terreno productivo, capaces de propiciar la recomposición en sus filas y que le permita ligarse estrechamente a las expresiones avanzadas del movimiento altermundialización, aportando su propio legado de lucha a través de la socialización de su exitosa experiencia ${ }^{22} y$ de la constitución de la mencionada confederación latinoamericana de deudores $y$ ahorradores de la banca. Aquí es perceptible una contradicción que posiblemente introducirá nuevas tensiones en la definición identitaria y el accionar de los barzonistas: por un lado, estos pretenden dejar de reconocerse en tanto que deudores, y por otro, construyen un marco de significación y organización para unirse a deudores y ahorradores del resto de Latinoamérica.

A lo largo de los ocho años de vida de la organización, encontramos interesantes características en su accionar que debemos mencionar, tales como la existencia de una dirección colectiva con representación de todos los estados, con niveles importantes de autonomía en el ámbito local respecto de la dirección nacional, manteniendo relaciones de respeto y cooperación con barzones locales no incorporados a la estructura nacional, así como una relación plural con los partidos políticos. El tipo de acciones instrumentadas poseen, en términos generales, un fuerte impacto mediático, $y$ han sido dirigidas contra bancos, organismos financieros $y$ dependencias gubernamentales, e introducen fuertes dosis de

En este sentido, la dirigencia barzonista mantiene contacto directo con las dirigencias de los demás países, transmitiendo su metodología de trabajo $y$ el contenido de su repertorio de acción, en ocasiones acudiendo directamente a los respectivos países, $y$ de forma permanente, a través de su sitio internet (www.elbarzon.org). ritualidad en la que se combinan permanentemente música $y$ humor, incorporando maquinaria agrícola y caballos como elementos permanentes de la emblemática puesta en escena.

Haciendo un rápido balance de esta experiencia de lucha, el barzonismo partió de una lucha estrictamente reivindicativa y rápidamente llegó al nivel de lo político, debido a la presencia en el movimiento de cuadros dirigentes con trayectoria partidista, a una cultura política estadocéntrica profundamente arraigada que lleva a la acción social a orientar sus pasos hacia la cúspide del poder estatal, así como a la actitud de cerrazón del Estado que propició la nacionalización y la politización de la lucha. El Barzón Unión reivindica actualmente la dimensión ciudadana de los derechos económicos, sin alcanzar sin embargo, el nivel de las orientaciones ético-culturales del modelo económico nacional (sobre todo su orientación productivista). Esto es así aunque en su discurso hace una crítica radical a la manera actual de construir la política en este dominio, así como a su orientación neoliberal, $y$ a pesar de que encuentra en los barzonistas una concepción solidaria de las relaciones económicas, que no renuncia al mercado ni apuesta todo a la intervención estatal. Se trata de una acción social que combina oscilatoriamente diversas lógicas de acción: por un lado, el nivel de las demandas económicas y del intento de gestión de recursos (acción reivindicativa), por otro, la presión política hacia las instancias de gobierno y el sistema financiero (grupo de presión), por otro más, la disputa política autónoma (fuerza política) y desde los partidos existentes (corriente política). Por otro lado, la posición defendida por los barzonistas sugiere la superación de una noción abstracta de individuo, y representa, en cambio, la articulación de los derechos económicos ciudadanos con los de los distintos sectores que constituyen la movilización. Es quizás por la vía del impulso de una cultura cívica que combine lo universal y lo particular en su modelo de ciudadanía, que pueda pensarse en el posicionamiento del barzonismo en el nivel de la historicidad touraineana.

Otra particularidad de esta experiencia social es su constitución en red, lo que nos permite hablar de una corriente general de movilización 
social (el barzonismo), que tiene ejes organizacionales diversos (los barzones nacionales) los cuales no participan de manera necesaria ni simultánea en los mismos conflictos concretos. Profundizando esta lectura, descubriremos que, incluso al seno de cada organización, existe una fuerte heterogeneidad a lo largo y ancho del país, en lo concerniente a sus conflictos regionales $y$ locales, sus narrativas, sus repertorios y sus temporalidades de acción. Hay, desde esta perspectiva, grados diferentes y coexistentes de institucionalización, visibilidad y reflexividad, según la región o el sector, en el mismo horizonte temporal, lo que arroja analíticamente dinámicas plurales y no necesariamente en armonía al interior del mismo actor colectivo.

Sin embargo, a pesar de su carácter reticular, podemos reconstituir los trazos de una identidad que operó durante casi una década con bastante eficacia. Así, podemos sostener la coexistencia de corrientes y de mecanismos de identificación a niveles diferentes, que tienen enclaves múltiples: organizacionales, sectoriales, regionales o nacionales. Sin embargo, prevalecieron cuatro ejes que han organizado identitariamente al conjunto de la movilización: el conflicto financiero que afecta a todos los barzonistas; la apelación en su discurso, y con efectos unificadores crecientes, a las figuras del ciudadano, el productor y el consumidor; el rol protagónico del Barzón Unión, que jala y da una direccionalidad general al conjunto de la movilización y, finalmente, el tratamiento no diferenciado que los medios de comunicación hacen de la acción de los distintos barzones, lo que da, por exterioridad, un marco de identificación general común.

En síntesis, el barzonismo vio la luz en el contexto de la combinatoria de la crisis del modelo nacional-popular $y$ del advenimiento del modelo neoliberal. Este factor ha propiciado planteamientos de lucha y formas novedosas de organización y acción, al lado de formas de caudillismo, culto a la personalidad, corporativismo y una cierta nostalgia por la capacidad resolutiva del Estado, que se expresó en la fuga hacia arriba de los barzonistas en el periodo 19962000. A pesar de ello, por su composición, por sus modalidades de organización y acción, por el conflicto del que forman parte constitutiva $y$ por sus logros ${ }^{23}$, El Barzón ha sido sin duda una de las movilizaciones sociales más importantes del México de la transición política bajo el auge neoliberal.

\section{BIBLIOGRAFÍA}

Aguilar, Luis. "Transición democrática... y muchas cosas más". En: Labastida, Julio y Antonio Camou (coords.). Globalización, identidad y democracia. México y América Latina. México. S. XXIUNAM. 2001, pp.250-259.

Alonso, Jorge. "Expectativas y decepciones". En: Osorio, Joaquín (coord.). Fox a un año de la alternancia. Guadalajara. ITESO. 2001, pp.13-29.

Camou, Antonio. "Partidos políticos y gobernabilidad democrática en el México del postajuste (o de cómo ejercer democráticamente el gobierno y no morir en el primer intento). En: Labastida, Julio y Antonio Camou (coords.). Globalización, identidad y democracia. México y América Latina. México. S. XXI-UNAM. 2001, pp. 219-231.

Carton de Grammont, Hubert. El Barzón. Clase media, ciudadanía y democracia. México. IIS/UNAM, Plaza y Valdés. 2001.

Eckstein, Susan. “QQué ha sido de todos los movimientos? Los movimientos sociales

23 Liliana Flores estima (en entrevista citada), que de un universo inicial de 2 millones de expedientes de deudores en cartera vencida, restaba para el 2002 un número aproximado de 20 mil. Por un lado, los programas de reestructuración propuestos por el gobierno y la banca para desactivar el conflicto han permitido reducir sustancialmente esa cantidad; por otro, las negociaciones permanentes llevadas en paquete por los barzones estatales $y$ por la dirección nacional, han capitalizado esas condiciones para acelerar el proceso de solución global del conflicto. 
latinoamericanos en vísperas del nuevo milenio". En: Eckstein, Susan (coord.). Poder y protesta popular. Movimientos sociales latinoamericanos. México. S. XXI, 2001.

Garretón, Manuel Antonio. "Democratización política pendiente $y$ transformaciones societales. Las consecuencias para la acción colectiva y la cultura política". En: Labastida, Julio y Antonio Camou (coords.). Globalización, identidad y democracia. México y América Latina. México. S. XXI-UNAM. 2001, pp. 59-66.

Lechner, Norbert. 1995. Los patios interiores de la democracia. México. FCE. 1995, 183p.

Olvera, Alberto. "Conclusión”.En: Olvera, Alberto (coord.). La sociedad civil. De la teoría a la realidad. México. El Colegio de México.1999, pp. 339-362.

Ramírez Cuellar, Alfonso. "México: el desastre bancario". Ponencia presentada en el Foro Transforming the Global Financial System, en Montreal, Canadá. 2000.

Ramírez Sáiz, Juan Manuel y Jorge Regalado Santillán. "Introducción". En: Ramírez, Juan Manuel y Jorge Regalado (coords.). El debate nacional. Los actores sociales. Tomo 4. México. UdeG-Diana. 1997, pp. 11-29.
Ramírez Sáiz, Juan Manuel. "Instituido e instituyente: los actores de la innovación política en México". En: Ramírez, Juan Manuel y Jorge Regalado (coords.). Cambio político y participación ciudadana en México. México. CEPCOM-UdeG. 2000, pp. 25-56.

Rea, Carlos. "Le barzonisme: un nouveau mouvement social au Mexique?". Separata de Cahiers des Amériques Latines. IHEAL. París. 2002.

Torres, Gabriel. "El derecho de barzonear y sus efectos políticos". En: Alonso, Jorge y Juan Manuel Ramírez (coord.). La democracia desde abajo. México. Ed. La Jornada-CIIH/UNAM-CEEJ. 1997.

Zermeño, Sergio. "Epílogo: una perspectiva para la acción social en México". En: Zermeño, Sergio (coord.). Movimientos sociales e identidades colectivas. México en la década de los noventa. México. La Jornada-CIICH/UnAM. 1997, pp. 313-338.

"México: ¿Todo lo social se desvanece?". En: Labastida, Julio y Antonio Camou (coords.). Globalización, identidad y democracia. México y América Latina. México. S. XXI-UNAM. 2001, pp. 265-282. 
